\title{
Risk assessment and thromboprophylaxis for venous thromboembolism in the puerperium in a tertiary health facility in Nigeria
}

\author{
Mkpe Abbey $^{1 *}$, Kinikanwo I. Green ${ }^{2}$, Roseline Iheagwam $^{1}$, Chris Akani
}

\begin{abstract}
${ }^{1}$ Department of Obstetrics and Gynaecology, Rivers State University Teaching Hospital, Port Harcourt, Rivers State, Nigeria

${ }^{2}$ Department of Obstetrics and Gynaecology, University of Port Harcourt Teaching Hospital, Port Harcourt Rivers State, Nigeria
\end{abstract}

Received: 16 August 2021

Accepted: 01 November 2021

*Correspondence:

Dr. Mkpe Abbey,

E-mail: mkpeabbey@aol.com

Copyright: (c) the author(s), publisher and licensee Medip Academy. This is an open-access article distributed under the terms of the Creative Commons Attribution Non-Commercial License, which permits unrestricted non-commercial use, distribution, and reproduction in any medium, provided the original work is properly cited.

\begin{abstract}
Background: Venous thromboembolism (VTE) is a leading cause of maternal morbidity and mortality in the puerperium. Unfortunately in Nigerian tertiary institutions, there is paucity of information about its risk factors, screening for it, and its prophylaxis. The aim of the study therefore was to review the VTE risk and thromboprophylaxis in the puerperium at the University of Port Harcourt Teaching Hospital (UPTH), Nigeria.

Methods: A retrospective cross-sectional study carried out at the University of Port Harcourt Teaching Hospital (UPTH). The following data were extracted from the notes of 424 consecutive inpatients postnatal women who delivered from the 1st of January to the 30th of April 2020: history/demographic characteristics, risk factors for VTE using the RCOG Green top guideline No. 37a.of 2015 as a benchmark, thromboprophylaxis, diagnosis and treatment of VTE. Women with a VTE event in the preceding 4 months before pregnancy were excluded. Data was analysed using a statistical package for social science (SPSS) software, version 18.

Results: Risk assessment for VTE and its prophylaxis in the puerperium were not routine practice at the UPTH. 420 $(99.06 \%)$ out of the total 424 postpartum women that were assessed were at significant risk of developing VTE and therefore needed to be on thromboprophylaxis with low molecular weight heparin. Irrespective of the high prevalence of risk factors and the fact that $100(23.58 \%)$ of the patients had symptoms and signs of VTE, no case of VTE was recorded in the study population. Paucity of information and lack of knowledge about the diseases may be responsible for that.

Conclusions: $420(99.06 \%)$ out of the total 424 puerperal women were at significant risk of developing VTE and therefore needed to be on thromboprophylaxis in the puerperium. It was therefore recommended that a national guideline on VTE in the puerperium be written, taking into consideration local disease topography, ethnic diversity and the level of economic development in Nigeria.
\end{abstract}

Keywords: Risk assessment, Thromboprophylaxis, Venous thromboembolism, puerperium, Tertiary health facility

\section{INTRODUCTION}

Venous thromboembolism (VTE) is a leading cause of maternal morbidity and mortality in the developed world. ${ }^{1,2}$ The relative risk of VTE in pregnancy was increased four- to six-fold, and this was increased further postpartum. ${ }^{3-6}$ The absolute risk of VTE was however low with an overall incidence in pregnancy and the puerperium of 1-2 per 1000, but it peaked in the first 3 weeks postpartum. $^{4,7-11}$

There was paucity of information on the prevalence of VTE and its associated risk factors in Nigeria. ${ }^{12,13}$ 
There was clear evidence that identification of risk factors with subsequent thromboprophylaxis of the at-risk population will reduce the occurrence of morbidity and mortality caused by the disease. For instance, there was a significant fall in the United Kingdom (UK) in the maternal mortality rate from pulmonary embolism (PE) from 1.56 per 100000 maternities in 2003-2005 (33 deaths) to 0.70 per 100000 maternities in 2006-2008 (16 deaths). ${ }^{14,15}$ Therefore, VTE can be prevented by careful assessment of pre-existing and new-onset/transient risk factors, and employing optimum thromboprophylaxis. ${ }^{16}$

\section{Aim}

The aim of the study was to review the VTE risk and thromboprophylaxis in the puerperium at the University of Port Harcourt Teaching Hospital (UPTH), Nigeria with a view of determining those who would have needed VTE prophylaxis.

\section{METHODS}

The study was of retrospective cross-sectional design. It was carried out at the University of Port Harcourt Teaching Hospital (UPTH), Port Harcourt, Rivers State, Nigeria and it involved the puerperal population that delivered between 1st of January and 30th of April 2020.

\section{Process}

Files of 424 patients who delivered in UPTH between January 2019 and January 2020 were reviewed for the following information: history/demographic characteristics, risk factors for venous thromboembolism, thromboprophy-laxis, diagnosis of VTE and treatment of venous thromboembolism. Women with a VTE event in the preceding four months before the index pregnancy or those using concurrent antithrombotic therapy for other medical reasons were excluded. Data were collected by a dedicated research fellow who was trained in data collection on a semi-structured pretested validated questionnaire and then fed onto statistical package for the social sciences (SPSS) 2018. Preparation of the questionnaire was based on the Royal College of obstetricians and gynecologists guideline on reducing the risk of venous thromboembolism during pregnancy and the puerperium, United Kingdom as shown in Table $1 .^{17}$

\section{Determination of the sample size}

The primary outcome measure in the study was the number of patients in the puerperium that had risk factors for venous thromboembolism. Therefore, the sample size for the study was calculated by applying the sample size formula for cross-sectional study with a categorical outcome.

$\mathrm{n}=\mathrm{Z}_{1-\alpha / 2^{2}} \mathrm{P}(1-\mathrm{P}) / \mathrm{d}^{2} \quad$ where
$\mathrm{Z}_{1-\alpha / 2}$ - Standard normal variate. At 5\% type I error $(\mathrm{p}<0.05)$, it is 1.96 .

If we decide to raise the degree of precision with less error, i.e., at $1 \%$ type 1 error $(\mathrm{p}<0.01)$, it will be 2.58 . That will increase the power of the study. However, in many studies, $\mathrm{p}$ value is considered significant at $\mathrm{p}<0.05$. Therefore 1.96 was used in the present calculation of the sample size for the study.

$\mathrm{P}$ - Expected proportion in population based on previous studies.

$\mathrm{d}=$ Absolute error or precision.

There was no study in Nigeria at the time that the present study was carried out, that dealt with assessment of risk factors specifically in pregnancy, except the only one study that was carried out in Lagos State University Teaching Hospital as a part of an international multinational study. 18 Unfortunately the data from Nigeria was not analysed separately. The data from South Africa which was also part of the same international study was therefore used in the present study; it showed that 126 (57.2\%) patients out of the 220 women that were assessed were at risk of VTE during pregnancy and in the puerperium.

Therefore $\mathrm{n}=1.96^{2} \times 0.572(1-0.572) / 0.05^{2}$

$$
\begin{aligned}
& =1.96^{2} \times 0.572 \times 0.428 / 0.0025 \\
& =376.19=376 \text { Patients. }
\end{aligned}
$$

The required number of patients for the study was therefore 378. Giving allowance for attrition rate of $10 \%$, the final power for the study was $10 / 100 \times 376+376$

$$
=37.6+376=413.6=414 \text { Patients. }
$$

However, 424 patients were recruited for the study.

\section{Data analysis}

Data was entered into statistical package for the social sciences (SPSS) 2018 software for analysis. Simple proportions were used in the descriptive analysis. Quantitative data were summarized and presented as mean and standard deviation while qualitative data were presented as numbers and percentages. The women who were at risk of developing VTE were supposed to have been given LMWH as thrombo-prophylaxis according to the NICE guideline. ${ }^{17}$

\section{Ethical approval}

Ethical approval for the study was granted by the University of Port Harcourt Teaching Hospital ethical committee. 


\section{RESULTS}

\section{Socio-demographic and obstetric characteristics of the patients}

A total of 424 patient's notes were reviewed. Some of the demographic indices were not available for some of the patients. The availability was as shown in the Table 1. Age distribution was computed using the modified World Health Organization (WHO) standard age groups. ${ }^{19}$

The average age of the patients was $32.24 \pm 5.74$ years. The highest number of the patients was in the age bracket of 25-34 which constituted $200(53.19 \%)$ out of the total 376 patients whose age was available); this was followed by those in the age group 35-44 years which made up 138 (36.70 of the study population whose age was available, indicating that majority of the women had children late in life. Although the age group of more than 35 years was a low risk factor for venous thromboembolism, it could be associated with other factors and sum up to constitute a significant risk for the patients (Table 2).

The average weight of the patients was $77.04 \pm 14.93$ while the average body mass index (BMI) was $29.96 \pm 6.84 .78$ (35.78\%) out of the 218 women who had their BMI taken had BMI 30.0-34.9 (Class I Obesity) while 26 (11.93\%) and 12 (5.50\%) had BMI 35.0-39.9 (Class II Obesity) and $\geq 40.0$ (Class III obesity) respectively (Tables 1 ).

Patients that had class I and II obesity scored " 1 " each for venous thromboembolism risk while those who had Class III Obesity scored ' 2"' each (Table 2). 204 (48.11\%) out of the total 424 patients were Para 3 and above and therefore each of them scored 1 for venous thromboembolic risk (Tables 1 and 2). Risk of VTE that might be associated with other demographic factors (education, employment, education, social history and marital status) could not be assessed because none of the patients was diagnosed with VTE.

Risk of VTE that might be associated with other demographic factors (education, employment, education, social history and marital status) could not be assessed because none of the patients was diagnosed with VTE.

\section{Frequency of individual risk factors for venous thromboembolism}

The risk factors for venous thromboembolism were those factors, if present, could predispose to development of VTE during pregnancy or the puerperium. The Royal College of obstetricians and gynaecologists VTE guideline for screening and prophylaxis was adopted and used in the present study (Table 2). ${ }^{17}$

Each of the factors was given a number which is an indicator of the degree of the risk associated with it. The identified risk factors in the present study with their frequencies were as shown in Table 3 .
They were classified into high, intermediate and low risk categories.

Table 1: Demographic, obstetric and general characteristics $(\mathrm{N}=424)$.

\begin{tabular}{|c|c|c|c|}
\hline \multicolumn{2}{|c|}{$\begin{array}{l}\text { Demographic obstetric and } \\
\text { general characteristics }\end{array}$} & \multirow{2}{*}{$\begin{array}{l}\text { Frequency } \\
38\end{array}$} & \multirow{2}{*}{$\begin{array}{l}\% \\
10.11\end{array}$} \\
\hline Maternal & $15-24$ & & \\
\hline & $25-34$ & 200 & 53.19 \\
\hline$(\mathbf{n}=376)$ & $35-44$ & 138 & 36.70 \\
\hline \multirow{3}{*}{$\begin{array}{l}\text { Education } \\
(\mathbf{n}=334)\end{array}$} & Primary & 4 & 1.20 \\
\hline & Secondary & 78 & 23.35 \\
\hline & Tertiary & 252 & 75.45 \\
\hline \multirow{3}{*}{$\begin{array}{l}\text { Employme } \\
\text { nt }(\mathbf{n}=\mathbf{2 7 2})\end{array}$} & Employed & 120 & 44.12 \\
\hline & Unemployed & 96 & 35.29 \\
\hline & Self-employed & 56 & 20.59 \\
\hline \multirow{9}{*}{$\begin{array}{l}\text { Occupatio } \\
\text { n }(\mathbf{n}=382)\end{array}$} & $\begin{array}{l}\text { Applicant/unempl } \\
\text { oyed }\end{array}$ & 2 & 1.05 \\
\hline & Artisan & 3 & 1.57 \\
\hline & Business/trader & 138 & 36.13 \\
\hline & Civil servant & 72 & 18.85 \\
\hline & House wife & 30 & 7.85 \\
\hline & Nurse & 24 & 6.28 \\
\hline & $\begin{array}{l}\text { Professional } \\
\text { (accountant, } \\
\text { lawyer) }\end{array}$ & 8 & 2.09 \\
\hline & Student & 46 & 12.04 \\
\hline & Teacher & 54 & 14.14 \\
\hline \multirow{3}{*}{$\begin{array}{l}\text { Social } \\
\text { History } \\
(424)\end{array}$} & $\begin{array}{l}\text { Nil drinking/ } \\
\text { smoking }\end{array}$ & 200 & 94.34 \\
\hline & Drinking & 18 & 4.25 \\
\hline & Smoking & 6 & 1.42 \\
\hline \multirow{3}{*}{$\begin{array}{l}\text { Marital } \\
\text { Status } \\
(\mathbf{n}=\mathbf{3 0 0})\end{array}$} & Married & 280 & 93.33 \\
\hline & $\begin{array}{l}\text { Single, never } \\
\text { married }\end{array}$ & 20 & 6.67 \\
\hline & Single, divorced & 0 & 0 \\
\hline \multirow{2}{*}{$\begin{array}{l}\text { Parity } \\
\text { group } \\
(n=424)\end{array}$} & $<$ Para 3 & 220 & 51.89 \\
\hline & Para 3 and above & 204 & 48.11 \\
\hline \multirow{2}{*}{$\begin{array}{l}\text { Weight at } \\
\text { booking } \\
(\mathbf{n}=\mathbf{2 5 2})\end{array}$} & $<80 \mathrm{Kg}$ & 144 & 57.14 \\
\hline & $\geq 80 \mathrm{~kg}$ & 108 & 42.86 \\
\hline \multirow{6}{*}{$\begin{array}{l}\text { BMI at } \\
\text { booking } \\
(\mathbf{n}=218)\end{array}$} & $\begin{array}{l}<18.5 \\
\text { (Underweight) }\end{array}$ & 4 & 1.83 \\
\hline & $\begin{array}{l}18.5-24.9 \\
\text { (Normal weight) }\end{array}$ & 42 & 20.19 \\
\hline & $\begin{array}{l}25.0-29.9 \\
\text { (Overweight) }\end{array}$ & 54 & 24.77 \\
\hline & $\begin{array}{l}30.0-34.9 \text { (Class } \\
\text { I Obesity) }\end{array}$ & 78 & 35.78 \\
\hline & $\begin{array}{l}35.0-39.9 \text { (Class } \\
\text { II Obesity) }\end{array}$ & 26 & 11.93 \\
\hline & $\begin{array}{l}\geq 40.0) \text { (Class III } \\
\text { Obesity) }\end{array}$ & 12 & 5.50 \\
\hline
\end{tabular}


Scoring of the risk factors for VTE and the need for thromboprophylaxis

The risk factors were identified and scored with a view of determining the percentage of the women that would have needed thromboprophylaxis. The scoring was based on the RCOG guideline. ${ }^{17}$ The guideline was clear on the indications and the schedules for thromboprophylaxis based on the scores by each patient as shown in italics under Tables 2 and 4.
The low-molecular weight heparin that were normally used were enoxaparin (clexane) and dalteparin (fragmin). TED stockings were recommended for all that were at risk of developing VTE during admission Some patients scored 4-10 points while $204(96.23 \%)$ of them had either prolonged admission to hospital for more than 3 days or were readmitted after initial discharge from the hospital. The management plan was shown in Table 4.

Table 2: Risk factors assessment for VTE in the puerperium. ${ }^{17}$

\begin{tabular}{|c|c|}
\hline Risk factors & Score \\
\hline \multicolumn{2}{|l|}{ Pre-existing Risk factors } \\
\hline Previous VTE & 4 \\
\hline Any woman requiring antenatal LMWH & 4 \\
\hline Known high-risk thrombophilia & 4 \\
\hline Low-risk thrombophilia with a family history of VTE in a first-degree relative & 4 \\
\hline Readmission or prolonged admission ( $\geq 3$ days) in the puerperium & 3 \\
\hline \multicolumn{2}{|l|}{$\begin{array}{l}\text { Medical comorbidities e.g. cancer, heart failure; active systemic lupus erythematosus, } \\
\text { inflammatory polyarthropathy or inflammatory bowel disease; nephrotic syndrome; } \\
\text { type I diabetes mellitus with nephropathy; sickle cell disease; current intravenous drug } \\
\text { user }\end{array}$} \\
\hline $\mathrm{BMI} \geq 40 \mathrm{~kg} / \mathrm{m}^{2}$ & 2 \\
\hline Family history of VTE & 1 \\
\hline Known low-risk thrombophilia & 1 \\
\hline Age (> 35 years) & 1 \\
\hline Obesity $(\mathrm{BMI} \geq 30 \mathrm{Kg} / \mathrm{m} 2$ but $<40 \mathrm{Kg} / \mathrm{m} 2)$ & 1 \\
\hline Obesity (BMI $\geq 40 \mathrm{Kg} / \mathrm{m} 2)$ & 2 \\
\hline Parity $\geq 3$ & 1 \\
\hline Smoker & 1 \\
\hline Gross varicose veins & 1 \\
\hline \multicolumn{2}{|l|}{ Obstetric risk factors } \\
\hline Emergency caesarean section & 2 \\
\hline Elective caesarean section & 1 \\
\hline Multiple pregnancy & 1 \\
\hline Pre-eclampsia in current pregnancy & 1 \\
\hline Mid-cavity or rotational operative delivery & 1 \\
\hline Prolonged labour (> 24 hours) & 1 \\
\hline PPH (> 1 litre) or blood transfusion & 1 \\
\hline Preterm birth $(<37+0$ weeks $)$ in current pregnancy & 1 \\
\hline Stillbirth in current pregnancy & 1 \\
\hline \multicolumn{2}{|l|}{ Transient Risk Factors } \\
\hline $\begin{array}{l}\text { Any surgical procedure in pregnancy or puerperium except immediate repair of the } \\
\text { perineum, e.g. appendicectomy, postpartum sterilisation }\end{array}$ & 3 \\
\hline Hyperemesis & 3 \\
\hline Current systemic infection & 1 \\
\hline Reduced mobility, dehydration & 1 \\
\hline \multicolumn{2}{|l|}{ Total score } \\
\hline \multicolumn{2}{|l|}{ Name } \\
\hline \multicolumn{2}{|l|}{ Signature } \\
\hline
\end{tabular}


Table 3: Frequency of individual risk factors for VTE $(n=424)$.

\begin{tabular}{|c|c|c|c|}
\hline \multirow{2}{*}{$\begin{array}{l}\text { Categories of } \\
\text { risk }\end{array}$} & \multirow{2}{*}{ Risk factors } & \multicolumn{2}{|c|}{ Frequency N(\%) } \\
\hline & & Yes & No \\
\hline \multirow{4}{*}{$\begin{array}{l}\text { High risk - } \\
\text { LMWF at lease } 6 \\
\text { weeks post- } \\
\text { partum }\end{array}$} & Any previous VTE & $0(0)$ & $0(0)$ \\
\hline & Anyone requiring antenatal LMWH & $0(0)$ & $0(0)$ \\
\hline & High-risk thrombophilia & $0(0)$ & $0(0)$ \\
\hline & Low-risk thrombophilia and family history. & $0(0)$ & $0(0)$ \\
\hline \multirow{7}{*}{$\begin{array}{l}\text { Intermediate } \\
\text { risk: LMWH for } \\
10 \text { days } \\
\text { postpartum; } \\
\text { longer if risk } \\
\text { factor persists }\end{array}$} & Caesarean section in labour & $66(15.57)$ & $358(84.43)$ \\
\hline & Obesity (BMI $\geq 40$ kg/m²) & $12(2.83)$ & $412(97.17)$ \\
\hline & $\begin{array}{l}\text { Readmission or prolonged admission ( } \geq 3 \text { days) in the } \\
\text { puerperium }\end{array}$ & $408(96.23)$ & $16(3.77)$ \\
\hline & $\begin{array}{l}\text { Any surgical procedure in the puerperium except } \\
\text { immediate repair of the perineum }\end{array}$ & $0(0.00)$ & $424(100)$ \\
\hline & SCD & $6(1.42)$ & $418(98.58)$ \\
\hline & GDM with nephropathy & $8(1.89)$ & $416(98.11)$ \\
\hline & RVD complicated & $8(1.89)$ & $416(98.11)$ \\
\hline \multirow{18}{*}{$\begin{array}{l}\text { Two or more risk } \\
\text { factors - } \\
\text { Intermediate } \\
\text { risk; } \\
\text { < } 2 \text { risk factors - } \\
\text { Low risk }\end{array}$} & Age $>35$ years & $136(32.08)$ & $242(57.08)$ \\
\hline & Obesity $(\mathrm{BMI} \geq 30 \mathrm{Kg} / \mathrm{m} 2$ but $<40 \mathrm{Kg} / \mathrm{m} 2)$ & $104(24.53)$ & $320(75.47)$ \\
\hline & Parity $\geq 3$ & $204(48.11)$ & $220(51.89)$ \\
\hline & Smoker & $6(1.42)$ & $418(98.58)$ \\
\hline & Gross varicose veins & $16(3.77)$ & $408(96.23)$ \\
\hline & Elective caesarean section & $102(24.06)$ & $322(75.94)$ \\
\hline & Emergency antenatal C/S & $50(11.79)$ & $374(88.21)$ \\
\hline & Current pre-eclampsia & $76(17.92)$ & $348(82.08)$ \\
\hline & Family history of VTE & $0(0)$ & $0(0)$ \\
\hline & Low-risk thrombophilia & $0(0))$ & $0(0)$ \\
\hline & Current systemic infection (Puerperal sepsis) & $12(2.83)$ & $412(97.17)$ \\
\hline & Multiple pregnancy & $8(1.89)$ & $416(98.11)$ \\
\hline & Immobility, e.g. paraplegia, PGP, long- distance travel & $0(0)$ & $424(100)$ \\
\hline & Preterm delivery in this pregnancy $(<37+0$ weeks & $104(24.53)$ & $320(75.47)$ \\
\hline & Stillbirth in this pregnancy & $38(8.96)$ & $386(91.04)$ \\
\hline & Mid-cavity rotational or operative delivery & $2(0.47)$ & $422(99.53)$ \\
\hline & Prolonged labour (> 24 hours) & $52(12.26)$ & $372(87.74)$ \\
\hline & PPH > 1 litre or blood transfusion & $72(16.9)$ & $352(83.02)$ \\
\hline
\end{tabular}

Table 4: Scoring of the risk factors for VTE and the need for thromboprophylaxis $(n=424)$.

\begin{tabular}{|c|c|c|c|c|}
\hline Risk Scores & Frequency & Total N (\%) & Need for thromboprophylaxis. & Total \\
\hline 0 (No risk) & $0(0)$ & $0(0)$ & \multirow{2}{*}{$\begin{array}{l}\text { Mobilisation and avoid } \\
\text { dehydration. }\end{array}$} & \multirow{2}{*}{ Not needing LMWH } \\
\hline 1 (Low risk) & $4(0.94)$ & $4(0.94)$ & & \\
\hline 2 (mild risk) & $4(0.94)$ & $4(0.94)$ & $\begin{array}{l}\text { To consider } \\
\text { thromboprophylaxis for at least } \\
10 \text { days }\end{array}$ & \multirow{9}{*}{$\begin{array}{l}\text { Needing or } \\
\text { considered for } \\
\text { LMWH }\end{array}$} \\
\hline 3 (Intermediate risk) & $34(8.02)$ & $34(8.02)$ & $\begin{array}{l}\text { To give LMWH for } 10 \text { days } \\
\text { postpartum but extend beyond } \\
10 \text { days if risk persist. }\end{array}$ & \\
\hline 4 (High risk) & $60(14.15)$ & \multirow{7}{*}{$382(90.09)$} & \multirow{7}{*}{$\begin{array}{l}\text { To give LMWH for } 6 \text { weeks } \\
\text { postnatal. }\end{array}$} & \\
\hline 5 (High risk) & $104(24.53)$ & & & \\
\hline 6 (High risk) & $102(24.06)$ & & & \\
\hline 7 (High risk) & $68(16.04)$ & & & \\
\hline 8 (High risk) & $30(7.08)$ & & & \\
\hline 9 (High risk) & $8(1.89)$ & & & \\
\hline 10 (High risk) & $6(1.42)$ & & & \\
\hline Total & $424(100)$ & $424(100)$ & & \\
\hline
\end{tabular}


Table 5: Venous thromboembolism and its presentations $(n=424)$.

\begin{tabular}{|lll|}
\hline VTE and its presentations & Number of patients [frequency N (\%)] & No \\
\hline Pain in the calf & Yes & $390(91.98)$ \\
\hline Redness of the legs & $34(8.02)$ & $398(93.87)$ \\
\hline Tachycardia & $26(6.13)$ & $402(94.81)$ \\
\hline Tachypnoea & $22(5.19)$ & $406(95.75)$ \\
\hline Chest pain & $18(4.25)$ & $398(93.87)$ \\
\hline Pulmonary embolism & $26(6.13)$ & 0 \\
\hline Deep venous thrombosis & 0 & 0 \\
\hline Sudden death & 0 & $420(99.06)$ \\
\hline
\end{tabular}

Table 6: Association of signs and symptoms of VTE and actual VTE with its risk factors.

\begin{tabular}{|c|c|c|c|c|c|c|c|}
\hline \multirow{2}{*}{$\begin{array}{l}\text { VTE scores } \\
\text { (frequency) }\end{array}$} & \multicolumn{7}{|c|}{ Symptoms and signs and their frequencies } \\
\hline & No sign & Tachycardia & Chest pain & Tachypnoea & Calf pain & Leg redness & Sudden death \\
\hline 0 (0) & 0 & 0 & 0 & 0 & 0 & 0 & 0 \\
\hline \multirow{2}{*}{$1(2)$} & 1 & & & & & & \\
\hline & & 1 & & & & & \\
\hline $2(2)$ & 1 & 1 & & & & & \\
\hline 3 (17) & 15 & 1 & & 1 & & & \\
\hline $4(30)$ & 27 & & 2 & & 1 & & \\
\hline \multirow{2}{*}{$5(54)$} & 39 & 2 & 1 & 1 & 2 & 3 & \\
\hline & & & 2 & & 2 & & \\
\hline \multirow{2}{*}{$6(51)$} & 40 & 0 & 3 & 0 & 3 & 3 & \\
\hline & & & & & 1 & & \\
\hline \multirow{3}{*}{7 (34) } & 23 & 5 & 1 & 1 & 2 & 0 & 0 \\
\hline & & 1 & & & & & \\
\hline & & & Chest pain + & calf pain - 1 & & & \\
\hline \multirow{3}{*}{8 (17) } & 13 & 1 & 0 & 0 & 1 & 0 & 0 \\
\hline & & & Chest pain + & leg pain + sudc & n death $=1$ & & \\
\hline & & & & 1 & & & \\
\hline \multirow{2}{*}{9 (4) } & 2 & & & 1 & & 0 & 0 \\
\hline & & & Calf pain + & hest pain $=1$ & & & \\
\hline 10 (3) & 1 & & & & 1 & 1 & \\
\hline 424 & 162 & 50( & $58 \%)$ & & & & \\
\hline
\end{tabular}

Patients that presented with symptoms and signs of venous thromboembolism

Some of the patients that were admitted on the ward had symptoms and signs of VTE (Table 5). They were as follows: maternal tachycardia, dyspnoea, tachypnoea, chest pain, calf pain and redness of the calf. Some of them had associated risk factors for venous thromboembolism (Table 6). None of the patients with no risk factors for VTE had symptoms or signs of VTE. Out of the 2 patients that scored ' 1 ' each for risk of VTE, I of them had tachycardia, chest pain and tachypnoea while the other had no symptom (Table 6).
Out of the 4 patients that scored " 1 "' each for risk of VTE, 2 of them had tachycardia, chest pain and tachypnoea while the other had no symptom (Table 6). Out of the other 4 patients that scored ' 2 ', 2 had no symptom while the other 2 had tachycardia. 30, 2 and another 2 of the patients that had VTE scores of " 3 "' presented with no symptoms, tachycardia and tachypnoea respectively. The rest of the associations of the risk factors with the signs and symptoms of VTE were illustrated in Table 6.

\section{DISCUSSION}

The present study, although retrospective, was the second study in Nigeria, assessing the risk of VTE in the 
puerperium. The first was carried out in Lagos State University Teaching Hospital as a part of a multinational study. ${ }^{18}$ Unfortunately, the study unlike the one that was conducted in South Africa as a part of the same multinational study was not published separately and the prevalence of risk factors and VTE was not clearly pointed out. In the index study, a review of patients' notes was carried out to ascertain if puerperal VTE risk assessment was carried out or not. A retrospective VTE assessment was also performed, using the RCOG VTE guideline as a standard, with a view of identifying those patients who were at significant risk of developing VTE in the puerperium and therefore would have needed VTE prophylaxis. ${ }^{17}$

Unfortunately, none of the patients had risk assessment in the puerperium and consequently, none had VTE prophylaxis. There was no patient among the 424-study population that had retrospective VTE assessment who did not have at least 1 risk factor for VTE. 424 patients, 4 $(0.94 \%)$ scored ' 1 ' each for risk of developing VTE and therefore would not have needed LMWH in the puerperium according to the RCOG guideline. ${ }^{17}$ The advice for them would have been to mobilise and avoid dehydration. Irrespective of the presence or absence of other risk factors, 204 (96.23\%) of the patients had either prolonged admission to hospital for more than 3 days or were readmitted after initial discharge from the hospital. They scored ' 3 ' each for VTE risk and therefore belong to the intermediate risk category. They would have needed LMWH for 10 days postpartum and would have continued on it beyond 10 days if risk persisted.

Each of another $4(0.94 \%)$ and $34(8.02 \%)$ of the patients had VTE risk scores of ' 2 ' and ' 3 ' respectively and therefore belong to the mild and intermediate risk categories respectively. LMWH for 10 days or more would have been considered for the first group in the puerperium but in the second group, the recommendation would have been to give LMWH for at least 10 days in the puerperium and to extend beyond that if risk persisted.

What was peculiar about the findings was that a staggering number of patients $382(90.09 \%)$ out of the total 424 had VTE scores 4-10 and therefore they were classified as 'high risk category'. They would have needed LMWH for 6 weeks postnatal but they were not given. $420(99.06 \%)$ of the 424 patients scored 4-8 VTE risk points while 10 $(4.72 \%)$ scored $9-10$ points. Generally, it meant 210 $(99.06 \%)$ out of the total 424 patients that were assessed would have needed VTE prophylaxis in the puerperium in the form of at least LMWH. The findings were quite in contrast to what happened in the developed world, e.g. the United Kingdom where the percentage of patients that had significant risk factors for VTE was smaller and therefore the number of patients needing VTE prophylaxis in the puerperium was smaller. ${ }^{17}$ It was also significantly different from the finding of the multicentre study which showed that more than $50 \%$ but less than $90 \%$ of women during pregnancy and postpartum were at risk of VTE, and
$>90 \%$ received prophylaxis as per the guideline that was used. $^{18}$

High prevalence of risk factors was recorded at the background of poor account by patients of their medical history and poor medical knowledge of thrombophilia among healthcare professionals. There was no mention of any of the thrombophilic conditions in patient's notes. It meant, there would have been higher prevalence of risk factors in the study population by inference. Furthermore, irrespective of the high prevalence of risk factors, and the fact that $100(23.58 \%)$ of the patients had symptoms and signs of VTE, no case of VTE was recorded in the study population. Paucity of information and lack of knowledge about the diseases may be responsible for that. ${ }^{12,13,20}$

However, there was one case of sudden death and the VTE score of the patient was 8 . She also had symptoms of VTE, namely chest pain and leg pain. It might be that she had pulmonary embolism which was not diagnosed. It might as well be that the prevalence of the disease was so low that more power would have been needed to demonstrate its occurrence. Given that many of the patients did not go for follow-up after delivery, it might be that in the index project, some patients had the disease at home and either died or had spontaneous recovery.

\section{Limitations}

The study was retrospective and might not account for everything that occurred in those pregnancies. The study was powered enough to determine the prevalence of risk factors in the study population but not to ascertain the prevalence of VTE. There was no standard guideline for VTE risk assessment and prophylaxis among puerperal population in Nigeria. The benchmark for the study was the NICE guideline which at the time that the project was carried out, was used in the United Kingdom. The guideline might not be suitable for Nigerian population due to cultural, social and economic differences. Among the health professionals, there was probably limited knowledge of venous thromboembolic diseases, assessment of their risk and thromboprophylaxis; that was also applicable to the patients. Furthermore, there was no mention of thrombophilia in the notes; that may also represent another gap in knowledge.

\section{CONCLUSION}

The study showed that irrespective of the morbidity and mortality that VTE could cause, VTE risk assessment and prophylaxis were not practiced at the University of Port Harcourt Teaching Hospital in Nigeria. 408(96.23\%) of the patients had either prolonged hospital admission for more than 3 days or were readmitted after initial discharge from the hospital, $4(0.94 \%)$ and $34(8.02 \%)$ of the study population had VTE risk scores of ' 2 '" and ' 3 '" respectively and therefore belong to the mild and intermediate risk categories respectively and a staggering number of patients $382(90.09 \%)$ out of the total 424 
women had VTE scores 4-10 and therefore belong to the high-risk category. Generally, 420(99.06\%) out of the total 424 patients that were assessed would have needed VTE prophylaxis in the puerperium in the form of at least LMWH. Furthermore, irrespective of the high prevalence of VTE risk factors and the fact that 100 (23.58\%) of the patients had symptoms and signs of VTE, no case of VTE was recorded in the study population. Paucity of information and lack of knowledge about the diseases might be responsible for the result. However, one case of sudden death was recorded but the cause was not stated.

\section{Recommendations}

VTE is a major clinical concern with a substantial risk of morbidity and mortality in the puerperium. It was therefore recommended that a unified national guideline on thromboembolic risk assessment and prophylaxis be written, taking into consideration the Nigerian disease pattern, cultural diversity, level of economic development and the peculiarities of maternal care in Nigeria. Given that the present study was retrospective and not powered enough to determine the actual prevalence of VTE, it was highly recommended that a prospective better powered study be carried out and the created guideline be used as a benchmark for comparison. Knowledge of the disease could be improved by organizing seminars to educate obstetricians on the realities of the deadly health condition. There would also be the need to write patient's information leaflets which should go a long way educating patients. Patients could also have specific antenatal classes where they would be educated on VTE.

Funding: No funding sources Conflict of interest: None declared

Ethical approval: The study was approved by the Institutional Ethics Committee

\section{REFERENCES}

1. Kuriya A, Piedimonte S, Spence AR, CzuzojShulman N, Kezouh A, Abenhaim HA. Incidence and causes of maternal mortality in the USA. J Obstet Gynaecol Res. 2016;42(06):661-8.

2. Knight M, Kenyon S, Brocklehurst P, Neilson J, Shakespeare J, Kurinczuk JJ. Saving Lives, Improving Mothers' Care: Lessons learned to inform future maternity care from the UK and Ireland. Confidential Enquiries into Maternal Deaths and Morbidity 2009-2012. Oxford, UK: University of Oxford. 2014

3. Heit JA, Kobbervig CE, James AH, Petterson TM, Bailey KR, Melton LJ. Trends in the incidence of venous thromboembolism during pregnancy or postpartum: a 30-year population-based study. Ann Intern Med. 2005; 143:697-706.

4. Sultan AA, West J, Tata LJ, Fleming KM, NelsonPiercy C, Grainge MJ. Risk of first venous thromboembolism in and around pregnancy: a population-based cohort study. $\mathrm{Br} \mathrm{J}$ Haematol. 2012;156:366-73.

5. Pomp ER, Lenselink AM, Rosendaal FR, Doggen CJ. Pregnancy, the postpartum period and prothrombotic defects: risk of venous thrombosis in the MEGA study. J Thromb Haemost. 2008;6:632-7.

6. Jackson E, Curtis KM, Gaffield ME. Risk of venous thromboembolism during the postpartum period: a systematic review. Obstet Gynecol. 2011;117:691703.

7. Jacobsen AF, Skjeldestad FE, Sandset PM. Ante- and postnatal risk factors of venous thrombosis: a hospital-based case- control study. J Thromb Haemost. 2008;6:905-12.

8. Lindqvist P, Dahlbäck B, MarŜ́l K. Thrombotic risk during pregnancy: a population study. Obstet Gynecol. 1999; 94:595-9.

9. Kane EV, Calderwood C, Dobbie R, Morris C, Roman E, Greer IA. A population-based study of venous thrombosis in pregnancy in Scotland 1980-2005. Eur J Obstet Gynecol Reprod Biol. 2013;169:223-9.

10. Liu S, Rouleau J, Joseph KS, Sauve R, Liston RM, Young D, et al. Maternal Health Study Group of the Canadian Perinatal Surveillance System. Epidemiology of pregnancy-associated venous thromboembolism: a population-based study in Canada. J Obstet Gynaecol Can. 2009;31:611-20.

11. Virkus RA, Løkkegaard EC, Bergholt T, Mogensen $\mathrm{U}$, LanghoffRoos J, Lidegaard $\varnothing$. Venous thromboembolism in pregnant and puerperal women in Denmark 1995-2005. A national cohort study. Thromb Haemost. 2011;106:304-9.

12. Kamdem F, Ngahane BHM, Hamadou B, Mongyui A, Doualla MS, Jingi AM, et al. Epidemiology, Clinical Presentations and In-Hospital Mortality of Venous Thromboembolism at the Douala General Hospital: A Cross-Sectional Study in Cameroon, Sub-Saharan Africa. World J Cardiovasc Dis. 2008;8:123-32.

13. Korubo KI, O. N. Ekeke ON. Awareness of venous thromboembolism among doctors in a Nigerian tertiary centre. East Afr Med J. 2015;92(12).

14. Lewis G. The Confidential Enquiry into Maternal and Child Health (CEMACH). Saving Mothers' Lives: Reviewing maternal deaths to make motherhood safer - 2003-2005. The Seventh Report on Confidential Enquiries into Maternal Deaths in the United Kingdom. London: CEMACH. 2007.

15. Centre for Maternal and Child Enquiries (CMACE). Saving Mothers' Lives: Reviewing maternal deaths to make motherhood safer: 2006-08. The Eighth Report of the Confidential Enquiries into Maternal Deaths in the United Kingdom. BJOG. 2011;118:1-203.

16. Rath W, Tsikouras P, von Tempelhoff GF. Pharmacological Thromboprophylaxis during pregnancy and the puerperium: recommendations from current guidelines and their critical comparison [in German]. Z Geburtshilfe Neonatol. 2016;220(03):95-105.

17. Gris JC, Aoun J, Rzaguliyeva L, Begum R, Salah H, Tugushi T, et al. Risk Assessment and Management 
of Venous Thromboembolism in Women during Pregnancy and Puerperium (SAVE): An International, Cross-sectional Study. TH Open. 2018;2(2):116-30.

18. Al-Sabbak M. RCOG Greentop guideline No. 37a. Reducing the Risk of Venous Thromboembolism during Pregnancy and the Puerperium. Conference: scientific day of obstetric and gynecology. 2015.

19. Ahmad OB, Boschi-Pinto C, Lopez AD, Murray CJL, Lozano R, Inoue M. Age standardization of rates: a new WHO standard. World Health Organization. 2001.
20. Omunakwe HE, Ekeke ON, Korubo KI. Clinicians' awareness on thromboprophylaxis in cancerassociated thrombosis. Afr J Med Health Sci. 2015;14:135-9.

Cite this article as: Abbey M, Green KI, Iheagwam $\mathrm{R}$, Akani C. Risk assessment and thromboprophylaxis for venous thromboembolism in the puerperium in a tertiary health facility in Nigeria. Int J Reprod Contracept Obstet Gynecol 2021;10:4343-51. 